\title{
Keratocystoma of the Parotid Gland: A Report of Two Cases of an Unusual Pathologic Entity
}

\author{
Toshitaka Nagao, M.D., Hiromi Serizawa, M.D., Keiichi Iwaya, M.D., Tohru Shimizu, M.D., \\ Isamu Sugano, M.D., Yasuo Ishida, M.D., Kazuto Yamazaki, M.D., Michio Shimizu, M.D., \\ Tomoo Itoh, M.D., Akiyoshi Konno, M.D., Yoshiro Ebihara, M.D. \\ Department of Surgical Pathology, Tokyo Medical University Hospital (TN, HS, KI, TS, YE), Tokyo; \\ Department of Surgical Pathology, Teikyo University, School of Medicine, Ichihara Hospital (IS, YI, KY); \\ Department of Pathology, Saitama Medical University (MS); Department of Pathology, Hokkaido \\ University Hospital (TI), Hokkaido; and Department of Otolaryngology, Chiba University, School of \\ Medicine (AK), Chiba, Japan
}

\begin{abstract}
Benign salivary gland tumors composed of purely squamous cells are quite unusual and are not included in the World Health Organization classification. We have seen two benign parotid gland tumors characterized by multicystic spaces with stratified squamous linings and focal solid epithelial nests. Seifert et al. recently described such a case as a choristoma; we, however, herein propose a new designation, keratocystoma, for this unique tumor group, because of its distinctive histological features. These tumors occurred in men aged 18 and 38 years with enlarging parotid gland tumors. Both had largely similar gross and/histological features, with some variations. The epithelium lining of the cysts showed apparent keratinization through a parakeratotic or orthokeratotic pathway without forming a granular cell layer. Stratification of the epithelium was always regularly oriented from the outer basal to the inner keratotic cell layer. Focally, the outer layer had bud-like protrusions. In some areas, solid squamous cell islands surrounded by basement membrane were enclosed within the collagenous stroma. These cystic and solid structures were randomly distributed, showing no definite lobular architecture. All of the tumor cells had uniform, bland nuclei and abundant eosinophilic cytoplasm. Scattered mitotic figures were observed, limited to the outer epithelial layer, and showed no abnormal patterns. Transformation from the parotid ductal epithelium to the tumor cells is evident.
\end{abstract}

Copyright (C) 2001 by The United States and Canadian Academy of Pathology, Inc.

VOL. 15, NO. 9, P. 1005, 2001 Printed in the U.S.A.

Date of acceptance: May 20, 2002.

Address reprint requests to: Toshitaka Nagao, M.D., Department of Surgical Pathology, Tokyo Medical University Hospital, 6-7-1 Nishishinjuku, Shinjuku-ku, Tokyo 160-0023, Japan; e-mail: nagao-t@tokyo-med.ac.jp; fax: 81-3-3342-2062.

DOI: $10.1097 / 01 . M P .0000026053 .67284 . A 3$
Foci of foreign-body reactions against keratin materials were present. Immunoreactivities for cytokeratins reconfirmed the nature of squamous differentiation of the tumor cells. Ki-67-positive cells were confined along the outer basal layer of the tumor epithelium. Tests for $\alpha$-smooth muscle actin and S-100 protein were completely negative. Both patients had no evidence of recurrence 3 and 2 years after subtotal parotidectomy, respectively, without any additional therapy. We believe that this lesion represents a benign cystic neoplasm rather than a malignant tumor or pseudoneoplastic metaplastic condition. It is important to recognize that this peculiar benign tumor does originate from the salivary gland.

KEY WORDS: Benign tumor, Choristoma, Keratocystoma, Parotid gland, Salivary gland, Squamous cell carcinoma.

Mod Pathol 2001;15(9):1005-1010

Squamous cells are known to exist in a variety of salivary gland diseases. Of these, only squamous cell carcinoma is a neoplasm, consisting of cells that exhibit purely squamous differentiation, whereas benign salivary gland tumors composed mainly of squamous cells are unusual and are not included in the second edition of the World Health Organization classification of salivary gland tumors (1), nor in some well-known text books (2-6). Recently, Seifert et al. (7) introduced a case of previously unreported benign parotid gland tumor occurring in an 8-year-old girl; the tumor was characterized by the presence of multicystic spaces with stratified squamous epithelium containing keratotic lamellas and solid squamous epithelial masses, accompanied by focal calcification and foreign-body reaction. They classified this tumor as a choristoma because of its resemblance to tri- 
choadenoma of the skin. Until now, no additional such cases appeared to have been described in the literature.

We retrospectively reviewed 1921 cases of surgically resected primary parotid gland tumors deposited in our files and found two histologically identical cases reported by Seifert et al. (7). Because we believe that this lesion is a peculiar variety of salivary gland tumor, we propose a new designation, keratocystoma, to represent its specific histopathological features. Here, we describe the clinicopathological and immunohistochemical features of these two examples and discuss their possible nature in connection with the histopathological differential diagnosis.

\section{MATERIALS AND METHODS}

We examined two parotid gland tumor cases, exhibiting almost identical histopathological features to those reported by Seifert et al. (7), that were detected among 1921 surgically resected primary parotid gland tumors deposited in the files of Chiba University Hospital and other hospitals in Japan between 1953 and 2001. Several step tissue sections were fixed on $10 \%$ buffered formalin and processed using routine histological techniques, including periodic acid-Schiff (periodic acid-Schiff), Alcian blue, mucicarmine, and silver. For immunohistochemistry, the deparaffinized and rehydrated slides were boiled in $10 \mathrm{~mm}$ citrate buffer, $\mathrm{pH} 6.0$, for 20 minutes in a microwave oven. After cooling for 30 minutes, they were incubated with the primary antibody for 15 hours at $4^{\circ} \mathrm{C}$. The primary antibodies used in this study are listed in Table 1. The labeled streptavidin-biotin peroxidase method (LSAB Kit; DAKO, Glostrup, Denmark) was used for detection, employing 3,3'-diaminobenzidine as the chromogen. The sections were slightly counterstained with hematoxylin.

TABLE 1. Antibodies Used in This Study

\begin{tabular}{llll}
\hline $\begin{array}{c}\text { Antigen } \\
\text { (Antibody) }\end{array}$ & \multicolumn{1}{c}{ Source } & Clonality & \multicolumn{1}{c}{ Dilution } \\
\hline $\begin{array}{c}\text { Cytokeratin } \\
\text { (AE1/AE3) }\end{array}$ & $\begin{array}{c}\text { DAKO (Glostrup, } \\
\text { Denmark) }\end{array}$ & M & $(1: 50)$ \\
Cytokeratin 1 & DAKO & & \\
Cytokeratin 7 & DAKO & M & $(1: 100)$ \\
Cytokeratin 8 & Novocastra Lab. & M & $(1: 100)$ \\
& $\quad$ Newcastle, UK) & M & $(1: 60)$ \\
Cytokeratin 13 & DAKO & & \\
Cytokeratin 14 & Novocastra & M & $(1: 100)$ \\
Cytokeratin 17 & DAKO & M & $(1: 20)$ \\
Cytokeratin 18 & Novocastra & M & $(1: 40)$ \\
$\alpha$-Smooth muscle & Nichirei (Tokyo, Japan) & M & Prediluted \\
actin & & & \\
S-100 protein & DAKO & P & $(1: 500)$ \\
Collagen Type IV & DAKO & M & $(1: 100)$ \\
Ki-67 (MIB-1) & Immunotech S.A. & M & $(1: 200)$ \\
& $\quad$ (Marseille, France) & & \\
\hline
\end{tabular}

M, monoclonal; P, polyclonal

\section{RESULTS}

\section{Clinical Findings}

Case 1

An 18-year-old man presented with a painless right-sided parotid gland mass that had been present for 4 months. Because the tumor grew gradually from 10 to $20 \mathrm{~mm}$ in diameter over 2 months, the patient underwent aspiration cytology that provided a provisional diagnosis of mucoepidermoid carcinoma. No other foci of primary carcinoma were identified. A subtotal parotidectomy was performed 1 month later. The patient was alive 3 years after the surgery and had no evidence of recurrent disease.

\section{Case 2}

A 38-year-old man had noticed a small nodule in the left parotid gland area 12 months before admission. It had enlarged to reach $60 \mathrm{~mm}$ in diameter by time of physical examination. There was no tenderness or facial nerve palsy. Computerized tomography revealed a low-density multilocular cystic mass with enhanced septa in the left parotid gland, measuring $35 \times 42 \times 45 \mathrm{~mm}$ (Fig. 1). No cervical lymphadenopathy was detected. A subtotal parotidectomy was performed. Two years after the surgery, the patient was alive and had no evidence of recurrent disease.

\section{Pathological Findings}

The two cases had largely similar macroscopic and histological features. Grossly, the tumors existed within the parotid gland, and the cut surface

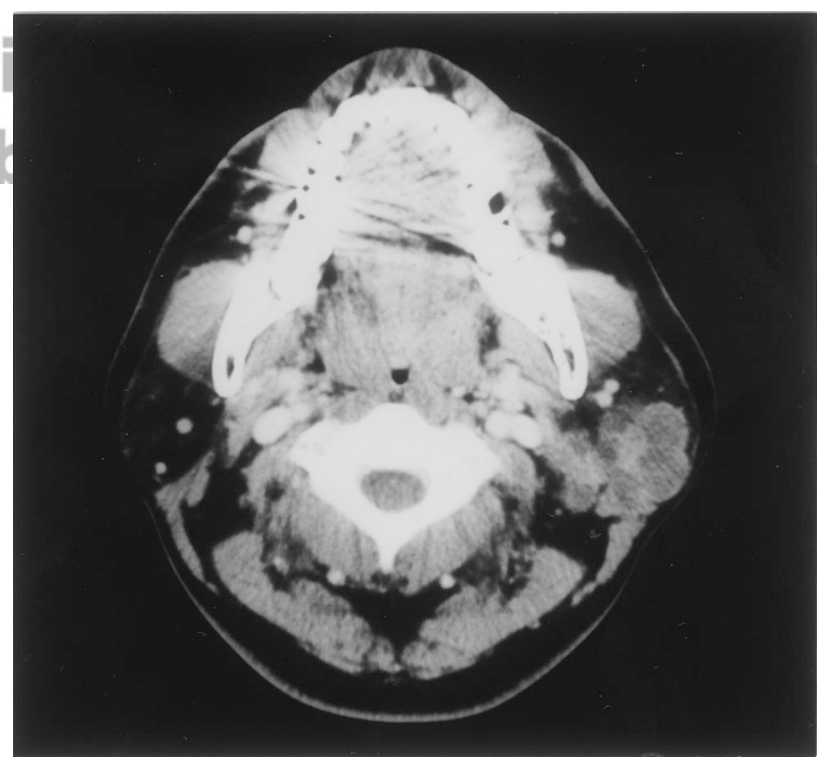

FIGURE 1. Case 2. Enhanced computed tomography scan, showing a low-density multilocular cystic mass with septa in the left parotid gland. 
showed multilocular cystic lesions filled with a keratin-like substance, measuring $40 \times 30 \times 15 \mathrm{~mm}$ and $40 \times 35 \times 30 \mathrm{~mm}$ in Cases 1 and 2, respectively (Fig. 2).

Histologically, the tumors consisted mainly of multiple cystic formations, containing lamellar keratin material (Fig. 3A). Although the cystic structures were variable in size and shape, they were larger (approximately $22 \mathrm{~mm}$ in diameter) and rounder in Case 2. The cystic spaces were lined with stratified squamous epithelium, which showed keratinization through the presence of parakeratotic or orthokeratotic cells, but without the formation of a granular cell layer (Fig. 3B). The stratification of the epithelium was always regularly oriented from the outer basal to the inner keratotic cell layers. Focally, the outer layer demonstrated bud-like protrusions. No skin appendages were found beneath the epithelium. Solid squamous cell islands with sharply defined margins were scattered and enclosed within the collagenous stroma (Fig. 3C). No myxochondromatous elements were identified. A low-power view showed that these cystic and solid tumor nests were irregularly distributed, without creating a definite lobular architecture. The squamous epithelial tumor cells had uniform, bland nuclei and abundant eosinophilic cytoplasm (Fig. $3 B, C)$. Scattered mitotic figures were present but limited to the outer layer of the epithelium. They displayed no abnormal features. The tumor epithelium was supported by a periodic acid-Schiff- and silver stain-positive basement membrane. No periodic acid-Schiff-, alcian-blue-, or mucicarminepositive mucous cells were detected among the tumor cells. Additionally, there was no sebaceous, hair-follicular, or oncocytic differentiation. In one area in each case, the salivary gland ducts displayed markedly thickened linings caused by proliferation of squamous cells, leaving residual lumina in the squamous cell nests (Fig. 3D). Solid tumor masses composed purely of squamous epithelium had apparently transformed from these structures. Foci of foreign-body reaction against keratin material caused by the rupture of the cysts were also seen. Microcalcification in the cystic content was seen in Case 2. The surrounding parotid gland tissue showed a moderate degree of chronic inflammatory cell infiltration and fibrosis, accompanied by acinar atrophy. However, no lobular necrosis or intraductal calculi were identified.

Immunohistochemically, in both cases the tumor cells were diffusely positive for cytokeratins AE1/ AE3 and 14 (Fig. 4A) but negative for cytokeratins 8 (Fig. 4B) and 18. Cytokeratins 1 and 7 were positive only in Case 1. Immunoreactivity for cytokeratins 13 and 19 was focally detected in both cases. $\alpha$-Smooth muscle actin and S-100 protein were completely negative. In the surrounding salivary glands, cytokeratins 7 and 14 and $\alpha$-smooth muscle actin were expressed in myoepithelial cells, whereas the ductal cells were immunoreactive for cytokeratins AE1/AE3, 7, 8, 18, and 19. Ki-67-immunoreactive cells were limited to the area along the outer basal layer of the tumor epithelium (Fig. 4C). The epithelium lining the cysts and the solid cell nests were surrounded by collagen Type IVpositive material.

\section{DISCUSSION}

The tumor presented here had histological features identical to those described by Seifert et al. under the term unusual choristoma, a possible counterpart of trichoadenoma (7), which is a rare benign skin tumor with hair follicle-like differentiation $(8,9)$. Although trichoadenoma superficially mimics our cases, several differences may be pointed out. For example, in trichoadenoma, the cystic spaces are more round and regular in shape, and keratinization of the cyst wall takes place with development of the granular layer $(8,9)$. Our cases thus constitute a rare type of salivary gland tumor, and keratocystoma seems to be a more appropriate designation by which to characterize the tumor histology than choristoma, which, by definition, is a cohesive tumor-like mass consisting of normal cells in an abnormal location $(10,11)$. In a comparison with adnexal tumors of the skin, Seifert et al. (7) postulated that the ectodermally derived oral and salivary gland epithelium may be the source of this tumor. In our cases, the tumor cells were apparently transformed from the salivary gland duct epithelium through a squamous metaplasia-like process. The squamous tumor nests showed no lobular arrangements, and the epithelial lining of the cysts demonstrated budding to form solid squamous cell islands. The keratinized squamous epithelium without granular layers is a unique feature of keratocystoma. From these facts, we are inclined to believe that this tumor is a true cystic neoplasm.

Several salivary gland tumors and tumor-like lesions containing squamous cells should be ruled out before the diagnosis of keratocystoma, including primary and metastatic squamous cell carcinomas, mucoepidermoid carcinoma, squamous metaplasia in certain benign neoplasias and conditions, and cysts. Primary squamous cell carcinoma of the parotid gland is an aggressive malignancy with frequent facial nerve involvement or cervical metastases $(12,13)$. Cystic changes are a wellknown finding in metaplastic nodal squamous cell carcinomas and are also noted in primary squamous cell carcinoma of the parotid gland (14). In keratocystoma, the consistent absence of metastasis, necrosis, invasion, and perineural or intravas- 


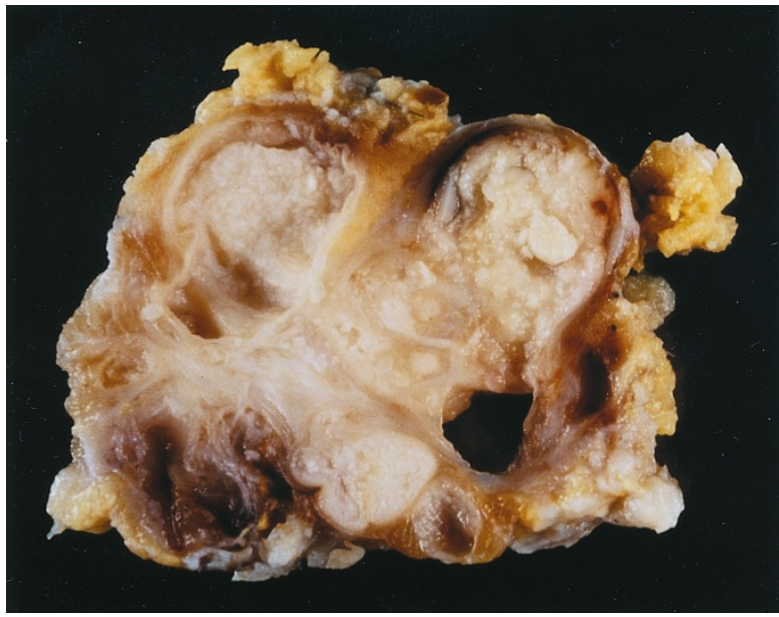

FIGURE 2. Case 2. Cut surface of the parotid tumor, showing multiple cystic formations filled with lamellar keratin material.

cular growth, as well as the lack of cytological atypia and minimal cell proliferative activity, weighs against a malignancy. The solid areas of squamous cell formation partly localized within the parotid gland parenchyma in the vicinity of an excretory duct should not be interpreted as invasive growth (7). In addition to the benign characteristics described above, the absence of incorporated mucous cells and the presence of marked keratinization are important for separating this tumor from mucoepidermoid carcinoma.

Squamous metaplasia is known to occur in several benign salivary gland tumors. In pleomorphic adenoma, squamous elements usually coexist with variable myxochondromatous, myoepithelial, or glandular components. Warthin's tumors sometimes show areas of squamous metaplasia, for example, in metaplastic (infarcted) Warthin's tumor. These areas, however, are usually accompanied by extensive necrosis (15-17), and immunoreactivity for cytokeratin may reveal columnar phenotypes but no squamous differentiation (18). In our cases, the cytokeratin expression largely corresponded to squamous differentiation.

Other additional lesions that can be mistaken for the tumors in our patients are necrotizing sialometaplasia and epidermal and dermoid cysts. Ne-

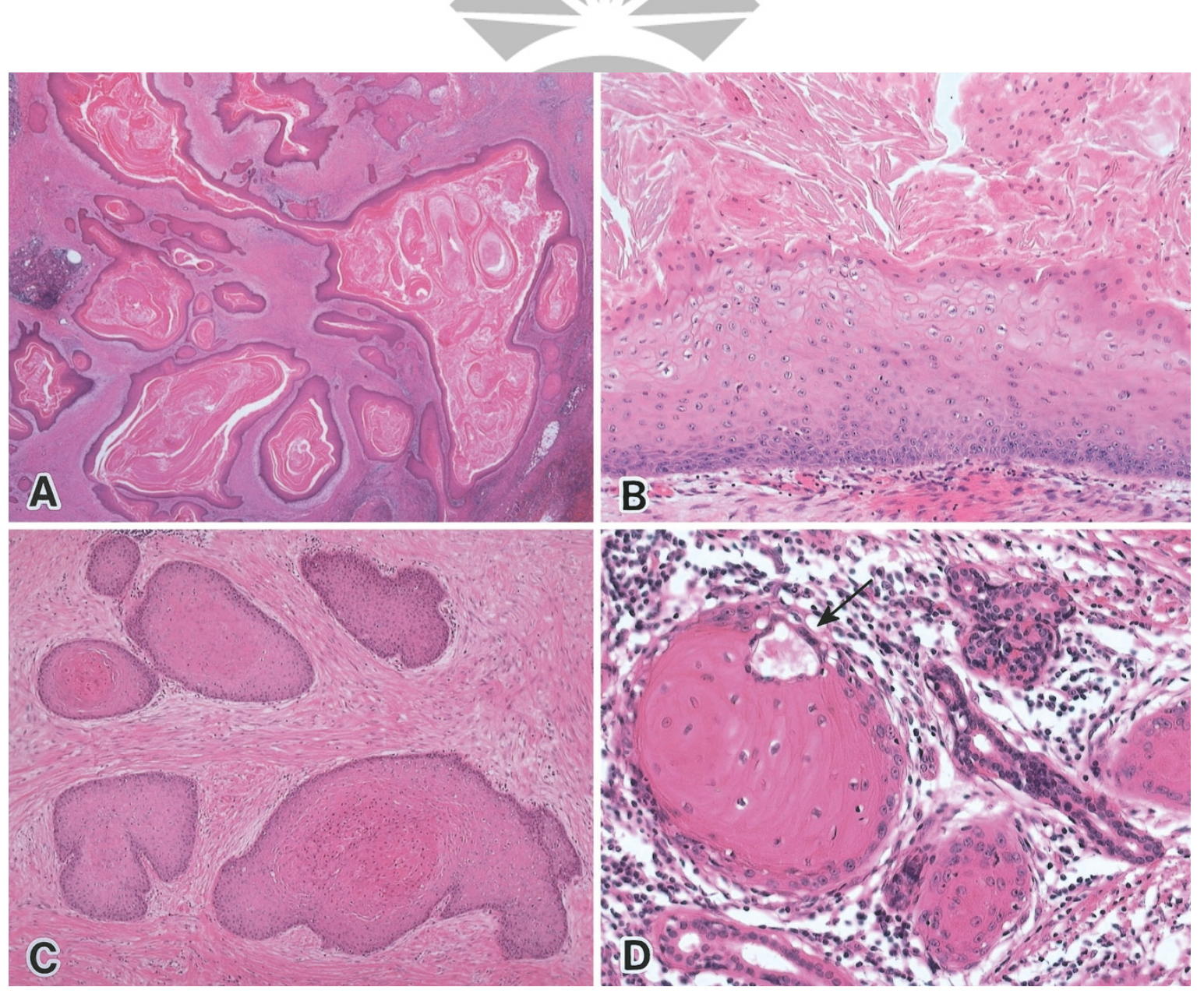

FIGURE 3. A, Case 1. Characteristic tumor view consisting of variably sized and shaped cystic lesions filled with lamellar keratin material. B, Case 2. Portion of the cyst wall showing stratified squamous epithelium with keratinization through parakeratotic cells. Note the lack of a granular cell layer. Tumor cells exhibit uniform, bland nuclei and abundant eosinophilic cytoplasm. C, Case 2. Solid squamous cell islands with sharply defined margins enclosed within collagenous stroma. D, Case 1. Solid masses composed of squamous epithelium in conjunction with parotid ducts. Note a residual duct lumen in squamous cell nests (arrow). 
crotizing sialometaplasia is an inflammatory and usually self-limiting disorder of the salivary glands (19-22) that occurs commonly in the hard or soft
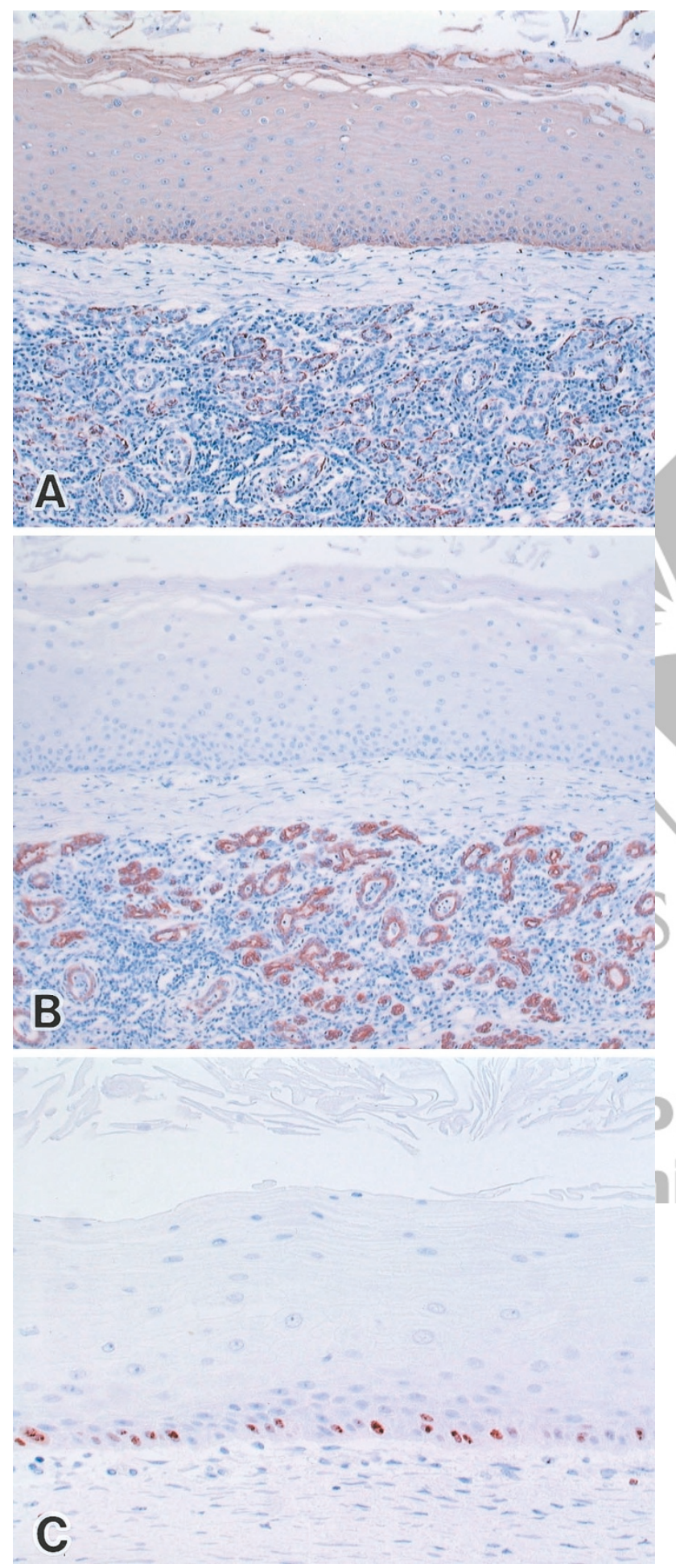

FIGURE 4. Case 1. Lining epithelium of the tumor (upper portion) showing diffusely positive for cytokeratin 14 (A) but negative for cytokeratin 18 (B). Note that in the surrounding parotid gland tissue (lower portion), positive immunoreactivity is seen in myoepithelial cells for cytokeratin 14 (A) and in ductal cells for cytokeratin 18 (B). C, Case 2. Ki-67-positive tumor cells are confined to the basal layer of stratified squamous epithelium of the tumor. palate but can also be found in the parotid gland (20). Histologically it is characterized by the following: (1) lobular infarction or necrosis; (2) blandappearing nuclear morphology of the squamous cells; (3) simultaneous metaplasia of ducts and acini; (4) prominent granulation tissue and inflammatory components; and (5) maintenance of the general lobular morphology despite the fairly extensive inflammatory and metaplastic changes, often involving more than one lobule (19). In brief, in keratocystoma, the lack of the first and last findings (Characteristics 1 and 5 from the previous list), along with the formation of much larger cysts and the absence of a granular layer in the squamous lining, may be helpful for distinguishing it from necrotizing sialometaplasia. Rarely, epidermal and dermoid cysts may occur in the parotid gland (2325). Most epidermal cysts show unilocular cystic formation with a granular layer in their linings (23). Unlike the case with dermoid cysts, skin appendages such as hair follicles and sebaceous glands were absent in our cases $(24,25)$.

Although the first report of keratocystoma presented a pediatric case, our experience indicates the possibility of adult occurrence. Keratocystoma is a completely benign tumor, and after subtotal parotidectomy, no additional therapy may be needed. Further observations, however, are required to exactly delineate the clinicopathological characteristics and suitable therapy of this rare tumor.

\section{BEFERENCES}

1. Seifert G, Sobin L. Histological typing of salivary gland tumors (World Health Organization). 2nd ed. New York: Springer-Verlag; 1991.

2. Ellis GL, Auclair PL. Tumors of the salivary glands. Washington, DC: Armed Forces Institute of Pathology; 1996.

3. Dardick I. Color atlas/text of salivary gland tumor pathology. New York: Igaku-shoin; 1996.

4. Cawson RA, Gleeson MJ, Eveson JW. Pathology and surgery of the salivary glands. Oxford: Isis Medical Media Ltd.; 1997.

5. Gnepp DR, Brandwein MS, Henley JD. Salivary and lacrimal glands. In: Gnepp DR, editor. Diagnostic surgical pathology of the head and neck. Philadelphia: W.B. Saunders; 2001.

6. Peel RL. Diseases of the salivary gland. In: Barnes L, editor. Surgical pathology of the head and neck. Marcel Dekker Inc.; 2001.

7. Seifert G, Donath K, Jautzke G. Unusual choristoma of the parotid gland in a girl: a possible trichoadenoma. Virchows Arch 1999;434:355-9.

8. Rahbari H, Mehregan A, Pinkus H. Trichoadenoma of Nikolowski. J Cutan Pathol 1977;4:90-8.

9. Ackerman AB, Reddy VB, Soyer HP. Neoplasms with follicular differentiation. 2nd ed. Ardor Scribendi Ltd.; 2001. p. 209-19.

10. Chou LS, Hansen LS, Daniels TE. Choristomas of the oral cavity: a review. Oral Surg Oral Med Oral Pathol 1991;72: 584-93.

11. Cotran RS, Kumar V, Collins T. Neoplasia. Robbins pathologic basis of disease. 6th ed. Philadelphia: W.B. Saunders; 1994. p. 243-4. 
12. Gaughan RK, Olsen KD, Lewis JE. Primary squamous cell carcinoma of the parotid gland. Arch Otolaryngol Head Neck Surg 1992;118:798-801.

13. Flynn MB, Maguire S, Martinez S, Tesmer T. Primary squamous cell carcinoma of the parotid gland: the importance of correct histological diagnosis. Annu Surg Oncol 1999;6:768-70.

14. Jayaram G, Verma AK, Sood N, Khurana N. Fine needle aspiration cytology of salivary gland lesions. J Oral Pathol Med 1994;23:256-61.

15. Seifert G, Bull HG, Donath K. Histologic subclassification of the cystadenolymphoma of the parotid gland: analysis of 275 cases. Virchows Arch A (Pathol Anat) 1980;388:113-38.

16. Eveson JW, Cawson RA. Infarcted ("infected") adenolymphomas: a clinicopathological study of 20 cases. Clin Otolaryngol 1989;14:205-10.

17. Di Palma S, Simpson RH, Skalova A, Michal M. Metaplastic (infarcted) Warthin's tumour of the parotid gland: a possible consequence of fine needle aspiration biopsy. Histopathology 1999;35:432-8.

18. Schwerer MJ, Kraft K, Baczako K, Maier H. Cytokeratin expression and epithelial differentiation in Warthin's tumor and its metaplastic (infarcted) variant. Histopathology 2001; 39:347-52.

19. Abrams AM, Melrose RJ, Howell FV. Necrotizing sialometaplasia: a disease simulating malignancy. Cancer 1973;32: 130-5.

20. Batsakis JG, Manning JT. Necrotizing sialometaplasia of major salivary glands. J Laryngol Otol 1987;101:962-6.

21. Brannon RB, Fowler CB, Hartman KS. Necrotizing sialometaplasia: a clinicopathologic study of sixty-nine cases and review of the literature. Oral Surg Oral Med Oral Pathol 1991;72:317-25.

22. Sneige N, Batsakis JG. Necrotizing sialometaplasia. Annu Otol Rhinol Laryngol 1992;101:282-4.

23. Pieterse AS, Seymour AE. Parotid cysts. An analysis of 16 cases and suggested classification. Pathology 1981;13:225-34.

24. Choi EC, Jin JB, Kim JY, Hong WP, Kim MJ, Park YK. Dermoid cyst of the parotid gland. Yonsei Med J 1988;29: 199-203.

25. Moody AB, Avery CME, Harrison JD. Dermoid cyst of the parotid gland. Int J Oral Maxillofac Surg 1998;27:461-2.

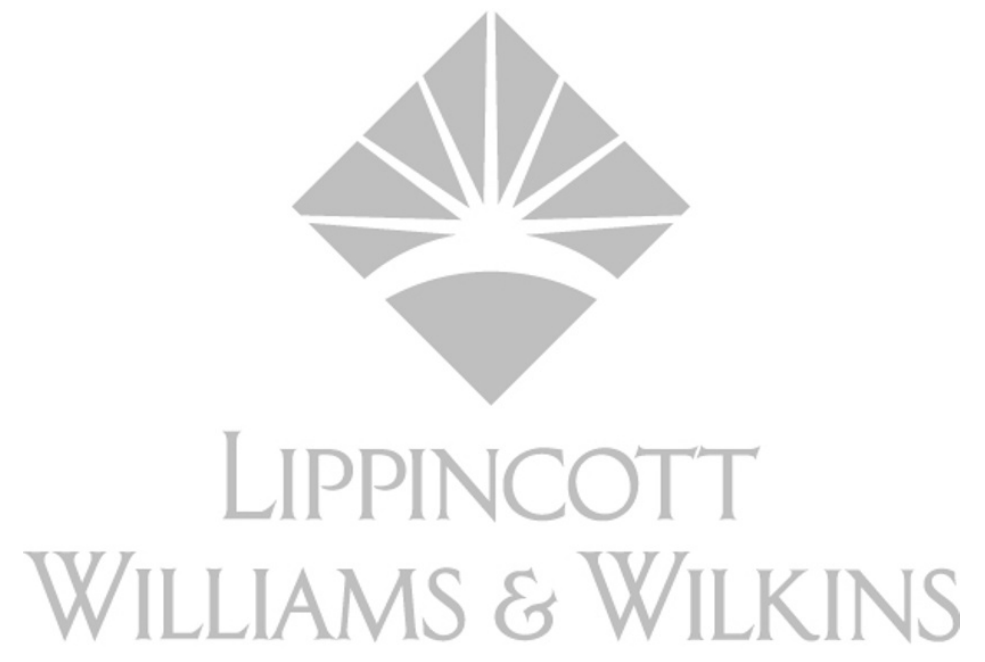

Unauthorized Use

\section{Errata}

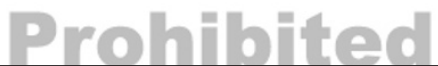

In the Modern Pathology July 2002 article "Increased p53 Protein Expression in Malignant Mammary Phyllodes Tumors" (Mod Pathol 2002;15(7):734-740), the figure legends were placed incorrectly. The correct placement is as follows:

Figure Legend 1 describes Figure 3

Figure Legend 2 describes Figure 4

Figure Legend 3 describes Figure 1

Figure Legend 4 describes Figure 2

The online version has already been corrected in departure from print.

In the Modern Pathology July 2002 article "The Distinction between Burkitt Lymphoma and Diffuse Large B-Cell Lymphoma with c-myc Rearrangement" (Mod Pathol 2002;15(7):771-776), the statement "There were no cases with dual translocation of c-myc or bcl-2 in our series" is incorrect. The correct statement is "There was a case with dual translocation of c-myc and bcl-2 is our series. Case 6 had both of the $\mathrm{t}(8 ; 22)(\mathrm{q} 24 ; \mathrm{q} 11)$ and $\mathrm{t}(14 ; 18)(\mathrm{q} 32 ; \mathrm{q} 21)$, and showed a diffuse proliferation of large lymphoma cells. This patient is alive during 32 months." 